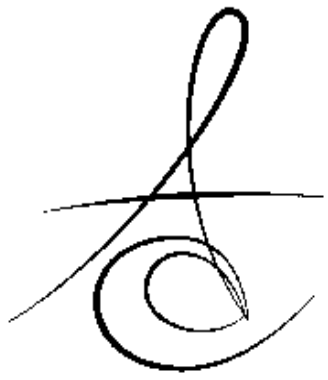

Makale Kodu/Article code: 1228

Makale Gönderilme tarihi; 09.07.2013

Kabul Tarihi: 24.09.2013

\section{SABİT BÖLÜMLÜ PROTEZLERDE FİBERLE GÜÇLENDİRİLMİŞ KOMPOZİT REZİN KULLANIMI}

\author{
THE USE OF FIBER REINFORCED COMPOSIT RESINS IN FIXED PARTIAL \\ DENTURES
}

Dt. Nurten BAYSAL*

Yrd. Doç. Dr. Simel AYYILDIZ*

\section{ÖZET}

Fiberle güçlendirilmiş kompozitlerin (FGK) diş hekimliğinde kullanımlarının giderek yaygınlaşması ile birlikte bu materyallerin protetik uygulamalardaki kullanımı da artmıştır. FGK mekanik ve fiziksel özelliklerinin geliştirilmesi minimal invaziv tedavi yaklaşımlarında yeni olanaklar sunmaktadır. FGK rezin restorasyonlar iyi bir estetik sağlarlar ve kolay yapım ve tamir aşamalarına sahiplerdir. Ayrıca tutuculuk ve destek dişe bağlanabilme kabiliyetinin iyi olması nedeniyle de tercih edilmektedirler. Bu derlemede, FGK'lerin özellikleri, sabit protetik uygulamalardaki yeri ve bu alandaki son gelişmeler değerlendirilmiştir.

Anahtar Kelimeler: Fiberle güçlendirilmiş kompozit rezinler, sabit bölümlü protezler

\section{ABSTRACT}

Obturators are prostheses used to replace maxillary With the increasing use of fiber-reinforced composites (FRC) in dentistry, the prosthetic applications of these materials also gain popularity at last years. Developments in mechanical and physical properties of FRC, offer new possibilities in minimally invasive treatment approaches. FRC resin restorations have good aesthetics, easy of construction and repair phases. Also, they are preferred because of their high ability of bonding to the retainer teeth and their retention capacity. In this review article, properties of FRC, the position in fixed prosthetic applications and recent developments in this field have been criticized.

Key Words: Fiber reinforced composite resins, fixed partial dentures

\section{GİRIş}

Protetik diş hekimliğinin en önemli hedefi çeşitli nedenlerle kaybedilmiş dişlerin ve ilgili çevre dokuların, uygun yapay malzemelerle yerine konulmasıdır. Böylece hastaya diş eksikliklerine bağlı olarak kaybedilen çiğneme, fonetik ve estetik fonksiyonları yeniden kazandırılmış olur. Yapılacak olan protetik restorasyonlar diş ve çevre dokuların bütünlüğünün ve sağlığının korunmasını sağlayacak şekilde tasarlanmalıdır. $\mathrm{Bu}$ nedenle günümüzde özellikle kısa dişsiz boşlukların tedavisinde, boşluğa komşu dişlerin mümkün olduğunca az prepare edildiği adeziv köprü protezlerin kullanımı yaygınlaşmaktadır.
Metal destekli seramik restorasyonlar diş hekimliğinde 40 seneden daha uzun bir süredir kullanılmaktadır. ${ }^{1}$ Metal destekli sabit protezler çok iyi klinik başarı göstermelerine rağmen uzun dönemde bazı dezavantajlara sahiplerdir. Özellikle soy olmayan metaller korozyona uğrayabilir ve bazı hastalarda allerjik reaksiyonlara yol açabilirler. ${ }^{2}$ Ayrıca metal alt yapıya bağlı olarak ortaya çıkan estetik problemler bu protezlerin kullanımını sınırlamaktadır. Metal seramik restorasyonların bu gibi dezavantajları hekimleri, bu restorasyonlara alternatif olan tam seramik sistemleri ve fiberle güçlendirilmiş kompozitleri (FGK) kullanmaya yöneltmiştir.

Son zamanlarda gerek materyaller, gerekse adeziv tekniklerinde meydana gelen gelişmeler FGK'e

* Gülhane Askeri Tıp Akademisi, Dişhekimliği Bilimleri Merkezi, Protetik Diş Tedavisi AD. 
ilgiyi arttırmıştır. Bu materyallerle diş yapısından daha az madde kaldırılarak yeterli tutuculuğa sahip restorasyonlar yapmak mümkün olabilmektedir. İhtiyaçlara cevap verecek şekilde uyumlanabilmesi bu materyallerin protetik kullanım alanlarını; sabit protetik restorasyonlar, post-kor sistemleri, hareketli protezler ve implant üst yapılarına kadar genişletmektedir. ${ }^{3}$

\section{Fiberle güçlendirme nedir?}

Fiber, uzunluğu çapından 100 kat daha fazla olan, silindirik, ince ve esnek lifli bir yapıdır. 'Kompozit' iki veya daha fazla bileşen içeren yapısal materyallere verilen addır. Bu bileşenler makroskobik düzeyde birleşirler ve birbirleri içinde çözünmezler. Bileşenlerden bir tanesi 'güçlendirici faz' adını alırken, ilave edildiği yapı ise 'matriks' adını alır. Diş hekimliğinde kullanılan FGK ise temel olarak rezin kompozitlere benzer yapıya sahiptir ve rezin kompozitlerdeki gibi organik matriks ve inorganik doldurucu fazdan oluşan iki kompozit yapının birleşimidir. FGK rezin köprülerde alt yapıyı fiberler oluştururken eksternal veneer yapıyı hibrid veya mikro dolduruculu kompozitler oluşturur., ${ }^{4,5}$ Güçlendirici komponent olan fiberler, dayanıklılık ve sertlik sağlarken, matriks yapı fiberleri bir arada tutan, kuvvetleri fiberlere dağıtan ve fiberleri çevresel etkilerden koruyan yapıdır.

\section{Dİ̧̧ HEKİMLİĞİNDE KULLANILAN FİBERLERİN SINIFLANDIRILMASI}

Diş hekimliğinde kullanılan fiberler;

- Fiberin tipine göre: Karbon-grafit fiberler, aramit fiberler, polietilen fiberler, cam fiberler ${ }^{3-5}$

- Fiberin oryantasyonuna göre: Tek yönlü paralel fiberler, iki yönlü sürekli fiberler, kısa- parçacık fiberler $^{3-5}$

- Fiberin monomer ile infiltrasyonunun önceden yapılıp yapılamamasına göre: Preinfiltre fiberler, non-preinfiltre fiberler ${ }^{3-5}$

Uygulama yeri, tipi ve yapısına göre fiberler Tablo 1'de piyasada bulunan ticari isimleri ile beraber sınıflandırılmıştır. Ancak yine de diş hekimliğinde fiberler genel olarak tiplerine göre anılırlar. Tiplerine göre fiberleri inceleyecek olursak;

Karbon-grafit fiberler; karbon fiberler ilk olarak 19. Yüzyılın sonlarına doğru Edison tarafından bambu çubuklarının karbonizasyonu ile elde edilmiş yapılardır. ${ }^{6}$ Sentetik olarak da poliakrilonitrilden elde edilirler. ${ }^{7}$ karbon fiberler ince tabakalardan oluşmuş grafitlerin birbiri içerisinde dağılmalarından meydana gelmişlerdir. ${ }^{4}$ Karbon fiberler ilk kez 1971 yılında Schreiber tarafından akrilik rezinleri güçlendirmek amacıyla kullanılmıştır. ${ }^{8,9}$ Siyah renkte olduğu için protezlerin posterior ve lingual kısımlarında kullanılabilirler. ${ }^{9}$ Günümüzde diş hekimliğinde karbon fiberler artan estetik beklentilerden dolayı hemen hemen hiç kullanılmamaktadır. ${ }^{3,4}$

Tablo 1. Fiberle güçlendirilmiş kompozitlerin (FGK) sınıflandırılması

\begin{tabular}{|c|c|c|c|c|}
\hline & Ürün & $\begin{array}{l}\text { Üretici } \\
\text { Firma }\end{array}$ & Fiber Tipi & $\begin{array}{l}\text { Fiber } \\
\text { YapıSI }\end{array}$ \\
\hline \multirow{2}{*}{$\begin{array}{l}\text { Laboratuvarda } \\
\text { Hazırlanan } \\
\text { Preinfiltre } \\
\text { Fiberler }\end{array}$} & Fiber Kor & $\begin{array}{l}\text { Jeneric/ } \\
\text { Pentron }\end{array}$ & S Cam & Doğrusal \\
\hline & Vectris & Ivoclar & E Cam & Doğrusal \\
\hline \multirow{2}{*}{$\begin{array}{l}\text { Klinikte } \\
\text { Hazırlanan } \\
\text { Preinfiltre } \\
\text { Fiberler }\end{array}$} & Everstick & $\begin{array}{c}\text { Stick Teck/ } \\
\text { Turku }\end{array}$ & E Cam & Doğrusal \\
\hline & Splint It & $\begin{array}{l}\text { Jeneric/ } \\
\text { Pentron }\end{array}$ & Cam & $\begin{array}{c}\text { Doğrusal, } \\
\text { Örgü }\end{array}$ \\
\hline \multirow{5}{*}{$\begin{array}{l}\text { Klinikte } \\
\text { Hazırlanan } \\
\text { Nonpreinfiltre } \\
\text { Fiberler }\end{array}$} & Connect & Kerr & \begin{tabular}{|l|} 
Polietilen \\
\end{tabular} & Örgü \\
\hline & Ribbond & Ribbond & Polietilen & Dokuma \\
\hline & GlasSpan & Exton & S Cam & Örgü \\
\hline & Stick & $\begin{array}{c}\text { Stick } \\
\text { Teck/Turku }\end{array}$ & E Cam & Doğrusal \\
\hline & StickNet & $\begin{array}{c}\text { Stick } \\
\text { Teck/Turku } \\
\end{array}$ & E Cam & Doğrusal \\
\hline
\end{tabular}

Aramit fiberler; aromatik poliamid fiberler için kullanılan jenerik isimdir. ${ }^{4}$ Aramit fiber; fiberi oluşturan materyalin en az \% 85 oranında amid bağlantısı ile direkt olarak iki aromatik halkaya bağlandığı, uzun bir zincirden oluşan sentetik materyaldir. ${ }^{14}$ Ticari olarak ilk defa DuPont tarafından Kevlar ismiyle üretilmiştir. ${ }^{15}$ Yüksek ıslanabilirlik gösterdiklerinden silan gibi bir ajanla işlenmesine gerek duyulmamaktadır. ${ }^{3}$ Renginin sarı olması nedeni ile estetik bölgelerde tercih edilmezler., Üst çene tam protezlerinin palatal ve posterior bölgeleri ile alt çene tam protezlerin lingual kısımlarında kullanılabilir. ${ }^{17}$ Kevlar fiberlerin protez kaide rezini içinde kullanıldıklarında toksik olduklarına dair herhangi bir bilgi yoktur ancak zamanla protez yüzeyinde ortaya çıkmaları mukoza irritasyonlarına yol

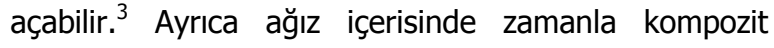
yüzeyinde açığa çıkan fiberler düzensiz bir yüzey oluşturarak hastayı rahatsız ederler. ${ }^{3}$

Polietilen fiberler; karbon-karbon çift bağı içeren bir hidrokarbon olan etilenin, serbest radikal polimerizasyonu ile oluşurlar. ${ }^{4}$ Polietilen fiberlerin renkleri doğal, yoğunlukları düşük ve biyolojik olarak da uyumludurlar ancak en büyük dezavantajları $140^{\circ} \mathrm{C}$ den sonra yapısal olarak bozulurlar ve bu nedenle

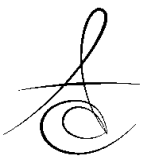


yüksek ISı ile polimerize olan kompozitlerle kullanılamazlar. ${ }^{4,19}$ Bunun yanında polietilen fiberlerin polimer kompozit ile adezyonundaki problemler ise diğer bir dezavantajıdır, nedeni ise polietilen fiberlerin yüzey enerjilerinin düşük olması ve hidrofobik olmaları sebebi ile ıslanabilirliklerinin az olmasıdır. ${ }^{20}$

Dokuma formunda hazırlanıp yüzeyi soğuk gazplazma uygulamasıyla modifiye edilmiş Dyneema (Dyneema B.V. Mauristlaan Urmond The Netherlands, Holland), Connect (MFG Co, West Collins Orange, CA, USA) ve Ribbond (Ribbond Inc Seatle, Wa USA) gibi polieten fiber sistemleri bulunmaktadır. ${ }^{21}$ Polietilen fiberler yumuşaktırlar, kolay kırılmayan renksiz ürünlerdir. Sıkıştırma altında düşük direnç gösterirler bu nedenle periodontal desteği zayıf dişlerde kullanılabilirler. ${ }^{22,23}$ En çok bilinen ve kullanılan polietilen fiber ise Ribbond'dur. Non-preinfiltre dokuma tip bir fiberdir, şekil verilebilir, şekil verilirken ve kesildiğinde açılmaz, dayanıklıdır. Ribbond'u diğerlerinden ayıran özellik; çaprazlama kilitli ilmek tarzında leno dalgası şeklinde olmasıdır. Bu yapı kuvvetlere karşı dayanıklıı̆ı arttırır. Gelen kuvvetler yapının içerisinde ilerler ve tekrar rezin içerisine transfer edilmezler. ${ }^{24}$

Cam fiber sistemleri; ana maddesi silisyum oksit $\left(\mathrm{SiO}_{2}\right)$, boron oksit $\left(\mathrm{B}_{2} \mathrm{O}_{3}\right)$, fosfor oksit $\left(\mathrm{P}_{2} \mathrm{O}_{5}\right)$ gibi oksitlerdir. ${ }^{25}$ Cam fiberler camın ince filamentler haline getirilmesi ile elde edilirler.

Cam fiberlerin E-cam, S-cam ve C-cam olmak üzere değişik türleri vardır. ${ }^{15}$ S-cam magnezyum alüminyum silikat yapısında ve yüksek elastik modülüne sahiptir. C-camların ise korozyona dirençleri yüksektir. ${ }^{26}$ Diş hekimliğinde FGK'de kullanılan cam fiber tipi ise genellikle alkalisiz camdan oluşan elektriksel cam olarak bilinen E-cam fiberlerdir. ${ }^{4}$ E-cam fiber temel yapısında \% $56 \mathrm{SiO}_{2}, \% 22 \mathrm{CaO}, \% 14 \mathrm{Al}_{2} \mathrm{O}_{3}, \% 6$ $\mathrm{B}_{2} \mathrm{O}_{3}$ ve az miktarda metal oksitler içeren boroalümina silika camdır. ${ }^{10,27}$

Nemli ağız ortamında polimer matriks boyunca difuze olan su E-cam fiber yüzeyinde korozyona neden olmakta ve fiberin mekanik özelliğini azaltmaktadır. ${ }^{28}$ Cilt ve gözle temas halinde irritasyon yapabilirler ve Restorasyonlardaki aşınmalara bağlı olarak yüzeye çıktıklarında ise doku irritasyonu, yoğun plak birikimi ve mukoza hasarına neden olabilirler. ${ }^{29}$

Cam ve polietilen fiberler translusent olmalarından dolayı protetik restorasyonlarda estetik açıdan başarılı bir şekilde kullanılırlar. Buna ek olarak cam fiberler ve polietilen fiberler farklı bükülme direncine sahiptirler. Polietilen fiberler, fiber demetlerini gerilim altında tutan kuvvete karşı yüksek dayanıklılık gösterirken basınç ve sıkıştırma kuvvetine karşı dayanıksızdırlar. Cam fiberler ise yükleme yönünden bağımsız olarak aynı özelliklere sahip oldukları için gerilme kuvvetlerine karşı olan dirençleri polietilen fiberlerden daha yüksektir. ${ }^{30}$

Cam fiber sistemlerinde en sık kullanılan markalar Vectris (Ivoclar, Vivadent AG Liechtenstein), Fiber-Kor (Jeneric Pentron, West Collins Ave Orange US), GlasSpan (Exton, Pa Pennsylvania USA), Stick (Stick Tech, Turku Finland) ve EverStick (Stick Tech, Turku Finland) dir. ${ }^{31}$ Karbon-grafit ve Aramit fiberlerin estetik özelliklerinin iyi olmaması nedeniyle adeziv köprülerin yapımında polietilen ve cam fiberler tercih edilir. ${ }^{4}$ Adeziv köprü yapımı için polietilen ve cam fiberler önceden rezinle emdirilmiş (FiberSpan, Vectris, FibreKor, Splint-It, EverStick) veya rezinle emdirilmemiş (Ribond, Conncet, GlasSpan, FibreSplint) olarak farklı özelliklere sahip sistemler şeklinde piyasada bulunmaktadırlar

\section{Fiberlerin mekanik özellikleri;}

Dental alaşımlar, seramikler ve kompozit rezinler üniform, homojen ve izotropik oldukları için, test edildikleri yön önemsenmeden her yönde aynı fiziksel ve mekanik özellikleri gösterirler. ${ }^{25}$ FGK'ler ise heterojen ve anizotropik yapıda oldukları için mekanik ve fiziksel özellikleri fiberlerin yerleşimine göre farklılık göstermektedir. ${ }^{27}$ Protetik uygulamalarda FGK'lerin en önemli mekanik özellikleri dayanıklı olmaları ve rijit yapılarıdır. ${ }^{25} \mathrm{Yu}$ ve ark. ${ }^{18}$. akrilik rezini güçlendirmek amacıyla, içerisine farklı fiber tiplerini farklı konsantrasyon ve kombinasyonlarda uygulamış, bunların sertlik, elastik modülü ve gerilme direncini incelemiş ve sonuçta aramit, polietilen ve cam fiberlerin akrilik rezinin dayanıklıığını arttırdığını bildirmişlerdir. Başaran ve ark. $^{6}$ ise CAD/CAM sistemi ile fiberle güçlendirilmiş ve güçlendirilmemiş kompozit rezin bloklardan sabit köprü protezler üretmişler ve bunların yük taşıma kapasitelerini karşılaştırmışlar, sonuçta fiberle güçlendirilmiş bloklar ile üretilen örneklerin yük taşıma kapasitesinin diğerlerine göre en yüksek olduğunu bildirmişlerdir.

Fiber yapılarının önemli bir avantajı da, artmış yorulma dirençleridir. Vallittu ${ }^{22}$ yaptığı bir çalışmada tek yönlü ve sürekli $E$ cam fiber içeren bir barı, 
yuvarlak çelik tel ve yarım yuvarlak çelik tel içeren barlarla karşılaştırmış; sonuçta hiç güçlendirme yapılmayan ve metal tellerle güçlendirilen barların 13 000 ile 39000 döngü aralığı sonucunda kırıldığını, cam fiberle güçlendirilen barların ise 100000 döngü sonucunda kırılmadığını belirtmiştir.

Mekanik ve fiziksel özelliklerinin iyi olmasına rağmen FGK'lerin elastik modülü veya restorasyonun sertliğine dikkat etmek gerekir. Metal alt yapılı porselenlerde olduğu gibi FGK'lerde de üst yapının gerilme direnci alt yapıdan düşüktür. Dolayısıyla mekanik problemler kompozit içersinde veya kompozit-fiber ara yüzünde oluşmaktadır. ${ }^{32}$ Yokoyama ve ark. ${ }^{14}$ adeziv rezin simanların mekanik özelliklerinin, FGK rezin köprülerdeki stress dağılımına olan etkisini sonlu eleman stres analizi ile incelemişler ve restorasyonların sağlıklı ve uzun ömürlü olması için uygun mekanik özellikleri olan adeziv rezin simanların seçilmesini önermişlerdir.

FGK'lerin dayanıklıı̆ını etkileyen faktörler beş kısımda incelenebilir:

1. Fiberlerin oryantasyonu; FGK'lerde kullanılan fiberlerin yönü, elde edilen kompozitin mekanik özelliklerini etkiler. FGK'ler üzerine uygulanan kuvvetin yönü fiberle paralel olmadığı zaman, mekanik özellikler azalır. $^{6,25,53}$ Örneğin köprü protezinin gövde bölgelerinde fiberler mesio-distal yönde yerleştirilmelidir. ${ }^{53}$ Dental kompozitleri kuvvetlendiren fiberler; tek yönlü, iki yönlü ve kısa parçacık şeklinde fiziksel formlarda bulunurlar. ${ }^{3}$ Tek yönlü fiberler; kompozit yapıyı tek yönde güçlendirerek kompozit yapıya anizotropik mekanik özellikler kazandırdıklarından dolayı en yüksek gerilim yönünün bilindiği durumlarda kullanılmaIıdır., ${ }^{3,6,15}$ İki yönlü fiberler dokuma ve örgü tarzında hazırlanır. Dokuma tipindeki fiberler, kompozite kuvvetin gelebileceği her yönde dayanıklıık sağladığından, uygulanacak kuvvetin yönünün bilinmediği durumlarda kullanılmaları gerekir. ${ }^{15}$ Kısa parçacık fiberlerin kompozit içerisine ilavesinde en büyük dezavantaj fiberlerin polimer içinde eşit dağılmaması ve belli bölgelerde yığılmasıdır. Bu nedenle kısa-parçacık fiberle güçlendirilen kompozitler, sürekli fiberle güçlendirilen kompozitler kadar güçlü olmazlar. ${ }^{10}$

2. Fiberlerin miktarı (oranı); fiberlerin matriks içindeki miktarıdır. Akrilik rezin polimer matriksinde fiber miktarındaki artışın test örneklerinde transvers ve çarpma dayanıklılığını arttırdığı gösterilmiştir. ${ }^{3,5,18}$ Fiber içeriği fazla olsa bile yoğunluğu düşük olan fiberler daha düşük dayanım kuvveti göstermektedirler. Cam fiberlerin özgül ağırlığı karbon, aramit ve UHMWP fiberlerden yüksek olduğu için eşit hacim oranlarında kullanıldıklarında, cam fiberler daha fazla kuvvetlendirme sağlamaktadır. ${ }^{27,32,34}$

3. Fiber yapıya monomer infiltrasyonu; her bir fiber yüzeyinin homojen olarak rezin matriks ile kaplanmasıdır. ${ }^{5,16}$ İki problemle karşılaşılabilir; ilki rezin matriksin fiber demetlerini yeterince Islatamaması, diğeri ise rezin matriksteki polimerizasyon büzülmesi sonucu fiberler arasında boşluklar oluşmasıdır. Bu boşluklar restorasyonun transvers yöndeki dayanıklılığını azaltır. ${ }^{5,16}$ Ağız sıvıları ile temas eden restorasyonda düşük doyurulmuş bölgelerdeki sıvı emilimi, mikroorganizmaların penetrasyonuna ve renk değişikliğine yol açabilir. ${ }^{3,16}$

Fiber yapıya monomer infiltrasyon işlemi iki şekilde uygulanmaktadır; ilki manuel olarak fiber bağları içine az viskoziteli rezin uygulanması işlemidir. ${ }^{5,37}$ Ancak manuel olarak rezinlerin doyurulma işlemi zordur. Bu nedenle fiberlerin üretim aşamasında farklı teknikler kullanılarak ön doyurma (pre-infiltrasyon/ pre-impregnated) işlemi uygulanmıştır. ${ }^{5}$ Ön doyurma işlemi; cam fiberlerin pöröz PMMA ile kaplanmasıdır. ${ }^{27} \mathrm{Bu}$ işlemde fiberler belirli pozisyonlarda üst üste yerleştirilerek, çeşitli kalınlıklarda fiber demetleri oluşturulur ve bu demetler basınçla polimerize edilir, bu sayede maksimum miktarda fiber polimer matris içine yerleştirilir. ${ }^{27}$ Mosharraf ve ark. ${ }^{16}$ yaptıkları bir çalışmada; pre-infiltrasyon yapılmış ve yapılmamış fiberlerle alt yapısı hazırlanan FGK rezin köprülerin kırılma direncini incelemişler ve bu iki gurup arasında önemli bir fark bulamamışlardır. Ancak hiç fiber alt yapı kullanılmayan grup ile fiber alt yapılı guruplar arasında anlamlı fark olduğunu ve fiberlerin sabit parsiyel köprülerin kırılma direncini arttırdığını bildirmişlerdir.

4. Fiberlerin matrikse bağlanma mekanizması, restorasyonun başarısı açısından önemli bir faktördür. 3,27 Fiber ile polimer matriks arasındaki kimyasal bağ, kovalent bağdır. Yapılan çalışmalar, bu bağlantının yeterli olmadığı durumlarda kompozitlerde su emiliminin arttığı ve mekanik özelliklerin azaldığını göstermiştir. ${ }^{3,16}$ Ayrıca uygun bağlantının; gerilim kuvvetinin matriksten fiberlere transferini kolaylaştırdığı ve bu sayede restorasyonun mekanik özelliklerini arttırdığı da belirtilmiştir. 3,37 Fiberin matrikse bağlanmasını güçlendirmek için fiber yüzeyinin silan, plazma,

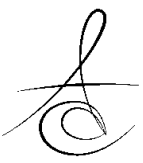


epoksi rezin vb. farklı yöntemlerle kaplanıp daha sonra monomer ya da polimer monomer karışımında bekletilmesi önerilir. Sfondrini ve ark. ${ }^{7}$ yaptıkları bir çalışmada; konvansiyonel ve nanodolduruculu FGK rezinlerin gerilme direncini üç nokta bükme testi ile incelemişler ve nanodolduruculu FGK rezinlerin yük taşıma değerinin daha yüksek olduğunu bildirmişlerdir.

5. Fiberlerin ve matriks polimerinin yanı sıra, veneer materyali olarak kullanılacak kompozitin de yeterli fiziksel özelliklere (yüksek aşınma direnci, yeterli estetik) sahip olması, oldukça önemlidir. ${ }^{3,5}$ FGK sistemlerde iki tip kompozit kullanılmaktadır; birincisi alt yapıyı sağlayacak fiber-kompozit, ikincisi ise dış yüzeyi oluşturacak veneer materyali olan hibrid veya mikrofil partiküle sahip kompozitlerdir. Fiberlerin restorasyon içindeki pozisyonları da önemlidir. ${ }^{5}$ Restorasyonun kırılmasının önlemesi için fiberler restorasyonda gerilimin en fazla olduğu bölgelere yerleştirilmelidir. $^{39}$ Sonlu elemanlar stres analizi ile yapılan çalışmalarda 3 üyeli köprülerde en çok stresin destek dişin dişsiz boşluğa bakan gövde ile bağlantı kısımlarında ve gövdenin dokuya bakan gingival yüzünde olduğu gözlenmiştir. ${ }^{40}$ Sonlu elemanlar stres analizi ile yapılan başka bir çalışmada ise inley köprülerde en fazla stres birikiminin prepare edilen destek dişin inley kavitelerinin servikal marjinlerinde ve konektör sahalarında olduğu görülmüştür. ${ }^{41}$ Dolayısıyla stresin yoğun olacağı bölgeler estetikten ödün verilmeyecek şekilde fiberle desteklenmelidir. Chen ve ark. $^{32}$ yaptıkları bir çalışmada; üç üyeli inley tarzında FGK rezin köprüler hazırlamışlar, bu köprülerde iki farklı fiber alt yapı dizaynı kullanmışlardır. Konvansiyonel dizaynda fiber bir inley kaviteden diğerine doğruca uzanırken, optimize dizaynda fiber pontik bölgesinin alt kısmından geçecek şekilde eğri bir kiriş gibi yerleştirilmiştir. Sonuçta optimize dizaynın kırılma direncinin ve yük taşıma kapasitesinin daha yüksek olduğunu belirtmişlerdir. Ayrıca örneklerin Xray görüntülerini almışlar ve konvansiyonel yöntemle hazırlanan test gurubunda kırıkların fiber alt yapı doğrultusunda optimize dizaynda ise konnektör alanlarında oluştuğunu bildirmişlerdir. ${ }^{32}$

\section{FGK Adeziv Köprülerin Avantajları}

Bu tip köprülerin avantajları genel olarak şu şekilde sıralanabilir;
1. Metallerin mekanik özelliklerine yakınlığı yanında rezinlerin estetik görünümlerine sahiplerdir ve manipulasyonları kolaydır. ${ }^{2,3,5,35,42}$

2. Herhangi bir mumlama, revetmana alma ve döküm işlemi olmadığı için laboratuar işlemleri kolaydır. 2,3,5,45

3. Yapımları tek veya en çok iki seansta tamamlanır. 3,5,45

4. Ekonomiktir. $3,5,46$

5. Resin simanla FGK restorasyon arasındaki bağlantı gücü, resin simanla metal arasındaki bağlantı gücünden $\% 50$ ile $\% 100$ daha fazladır. Adeziv bonding kullanımı marjinal sızıntıyı azaltır, retansiyonu arttırır. 5,35,36,46

6. FGK sistemle elde edilen protezler kompozitin mekanik özelliklerine bağlı olarak, karşıt diş minesini aşındırma riskini içermedikleri gibi kompozit sistemlerdeki yeni gelişmelere paralel olarak yeterli aşınma direnci ve sertlik gösterirler. ${ }^{2,5}$

7. Minimum diş dokusu kaybıyla son derece konservatif restorasyonlar yapılabilir ve supragingival preparasyonların yapılmasına olanak sağlar. 2,3,5,45,54

8. FGK restorasyonların bünyesinde oluşabilecek küçük kırık ve kopmalar kompozitlerle ağız içinde kolayca restore edilebilir. ${ }^{2-5,45}$

9. Korozyon ve metal alerjisi nedeniyle hastada; metal alaşımları ile çalışılmasından ötürü de laboratuar çalışanlarında ortaya çıkan akut ve kronik rahatsızlıklar FGK restorasyonlarda ortadan kalkar. $2,3,5,45$

\section{FGK Adeziv Köprülerin Dezavantajları}

1. Ağız sıvılarının yeterli derecede kontrol altına alınamadığı hastalarda uygulanması zordur. ${ }^{2}$

2. Parafonksiyonel alışkanlıkları olan hastalarda veneer kompozitin aşınması kaçınılmazdır. ${ }^{2}$

3. Çok üyeli köprülerde dişsiz boşluk arttıkça köprünün mekanik kuvvetlere karşı direnci azalır. Ayrıca uzun dişsiz boşluklara uygulanması ile ilgili yeterli klinik çalışma bulunmamaktadır. 2,3,45

4. Ağız içinde açıkta kalan fiber lokal doku reaksiyonuna neden olabilir. ${ }^{5,53}$

5. Renk stabilizasyonları zayıftır. ${ }^{2}$

6. Kompozitin tabakalar halinde uygulanmasına bağlı olarak tam polimerize olamayan bölgelerde fiber materyali ve kompozit arasında ayrılmalara neden olabilir. ${ }^{4,44}$

7. Fiber materyali yeterince radyoopak olmadığından radyografik olarak sekonder çürük teşhisi koymak

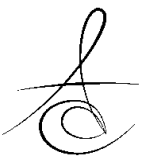


güçleşir. ${ }^{44}$

8. Klinik kron boyu kısa olan dişlerde, bağlantı bölgelerinde sorunlar görülebilir. ${ }^{3,45}$

\section{FGK Adeziv Köprülerin Endikasyonları}

1. Destek dişte konservatif preparasyonlar yapılması amaçlanıyorsa, ${ }^{2,4,5,46,54}$

2. Metal içermeyen ve porselen olmayan bir protez yapılması amaçlanıyorsa (özellikle metal alerjisi olan bireyler için önemlidir), 2,4,5,46,54

3. Geniş pulpaya sahip genç hastalarda daha az diş dokusu kaybı amaçlanıyorsa, 4,22

4. Destek dişlerin prognozu belirsiz ve daimi restoratif tedavi ertelenmek isteniyorsa uzun vadeli geçici protez olarak, $38,44,46,54$

5. Çene gelişiminin devam ettiği gelişme çağındaki hastalarda tek kanatlı olarak, ${ }^{4}$

6. Aşırı abrazyonları olan hastalarda sabit protez yapılması gerekiyorsa karşıt dentsiyonu porselenin aşındırıcı etkisinden korumak için, 2,4,5,8,46

7. Diş çekimi veya implant yerleştirilmesi sonrasında geçici protez olarak kullanılabilir. ${ }^{38,46}$

\section{FGK Adeziv Köprülerin Kontrendikasyonları}

1. Dişeti sıvısının kontrolünün iyi bir şekilde sağlanamadığı özellikle akut veya kronik gingival enflamasyonu olan hastalar ya da restorasyon marjinlerinin sulkusun içinde derin bir şekilde konumlandırıması gereken durumlarda, 2,42,46,54

2. Diş eksikliğinin fazla olduğu, iki veya daha fazla pontik konulması gereken uzun köprülerin yapılması gereken durumlarda, 2,4,5,42

3. Parafonksiyonel alışkanlığı olan hastalar, ${ }^{2,5,45,46,54}$

4. Karşıt dentisyonda uygun şekilde yapılmamış porselen veya hareketli bölümlü protezin iskelet parçası varsa, ${ }^{2,5}$

5. Alkol kullanan hastalarda, 2,5,42,54

6. Destek dişlerin kron boyu $5 \mathrm{~mm}$ 'den az ise, ${ }^{5,48,53}$

7. Oral hijyeni kötü olan hastalarda 5,46,54 kontrendikedir.

\section{FGK Rezin Köprüler}

FGK rezin köprüler laboratuvar ortamında (indirekt yöntem) ya da hasta başında (direkt yöntem) uygulanabilirler. Laboratuvarda üretilen sabit bölümlü protezlerin fabrikasyonunda ön doyurulmuş fiberler altyapı materyali olarak kullanılırken, üst yapı materyali olarak da seramikle güçlendirilmiş restoratif kompozitler (seromerler) kullanılmaktadır. ${ }^{37,47}$ Direkt yöntemle FGK köprü yapımında kullanılan fiberler rezin ile doyurulmalıdır veya rezinle doyurulmuş fiberler kullanılmalıdır $\mathrm{Bu}$ uygulamalarda kullanılacak olan kompozitler hibrid ya da mikrofil doldurucuya sahip olmalıdır. ${ }^{4}$ FGK rezin köprülerin yapımında; kompozit rezinden, akrilik veya porselen yapay dişten, ya da hastanın kendi dişinden gövde hazırlanabilir. $4,23,43$

Kompozit materyallerin en büyük dezavantajının polimerizasyon büzülmesi olduğu bilinmektedir. Laboratuvarda üretilen FGK restorasyonlar da (alt yapısı dahil) ışıkla polimerize olmakta fakat bununla birlikte ısıyla polimerizasyon işlemi, vakum ya da basınç uygulaması gerektirmektedir. Böylece ilave polimerizasyon ile alt yapıya daha yüksek bir eğilme dayanımı ve veneere daha fazla yüzey sertliği ile renk stabilitesi kazandırılmaktadır. ${ }^{2,50,51,53}$

Hasta başında yapılan FGK köprüler uygulanmadan önce eksik dişe komşu dişlerin oral yüzeylerine tutucu kaviteler açlarak (anterior restorasyonlarda lingual, posterior restorasyonlarda okluzal yüzeylere inley tarzında), eksik dişlerin yerine geçecek olan gövdeler ve bunları çevreleyen kompozitler fiberler yardımıyla komşu destek dişlere bağlanmaktadır. ${ }^{35}$ Bununla birlikte eğer restorasyon geçici amaçla kullanılacaksa işlemin geri dönüşü olması açısından yeterli interokluzal mesafe varsa preparasyon yapılmaması önerilir. ${ }^{5,31,54}$ Heuman ve ark. $^{12,13}$ yaptıkları çalışmalarda tutucu dişlere inley kavite, hibrid (bir dişe inley kavite-diğer dişe yüzey) ve sedece yüzeyden destek alan FGK rezin köprüler hazırlamışlar ve sonuçta ek mekanik retansiyonun anterior ve posterior FGK rezin köprülerin uzun dönem başarısını değiştirmediğini bildirmişlerdir. Bunun yanında Vallittu ve ark. ${ }^{46}$ birinci küçük azı dişi eksik olan hastaya, tutucu dişlerine preparasyon yapmadan sabit bölümlü protez yapmış ve vakanın 5 yıllık takibi sonucunda herhangi bir problem yaşanmadığını belirtmiştir.

FGK restorasyonlarda anterior ve posterior bölgelerde hazırlanan kavitelerde eski restorasyonlar ve mevcut olan çürükler tamamen kaldırılmalıdır. Preparasyon kenarları supragingival olmalıdır. FGK restorasyonların başarısını etkileyen en önemli faktörlerden biri de sıvı kontrolünün sağlanabilmesidir. $\mathrm{Bu}$ nedenle rubber-dam kullanılması ve supragingival preparasyonlar yapılması önerilir., ${ }^{4,5}$

a. Ekstrakoronal olarak tamamı FGK ile yapılan sabit protezler:

Ekstrakoronal olarak yapılan FGK rezin köprüler intrakoronal köprülere oranla daha komplike

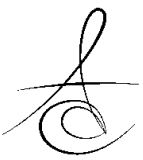


olmalarından dolayı sadece laboratuvar ortamında üretilmektedir. Ekstra koronal köprülerin yapım aşamalarına baktığımızda; öncelikli olarak 1.2-1.5 mm genişliğinde shoulder veya derin chamfer basamaklı diş preparasyonu yapılır. Bu preparasyon dişlerin tüm yüzeyini kapsayacak şekilde çepeçevre yapılmalıdır. Posteriorda destek dişlerin preparasyonu yapıldıktan sonra fiberin yerleşimine olanak sağlayan, dişlerin okluzal ve gövdeye bakan aksiyal yüzeyinde (basamağa ulaşmayan) oluk formunda, aksiyal ve okluzal derinlikleri $1 \mathrm{~mm}$ olan ikinci bir preparasyon yapılır. Anterior ekstra koronal köprü protezlerde ise destek dişlerin lingualinde bir basamak hazırlanır (Resim 1). Fiberin yerleşimine olanak sağlayan bu preparasyonlar sayesinde fiber alt yapı kolay şekillendirilebilir ve aşırı kontur oluşturulmaz. ${ }^{42}$

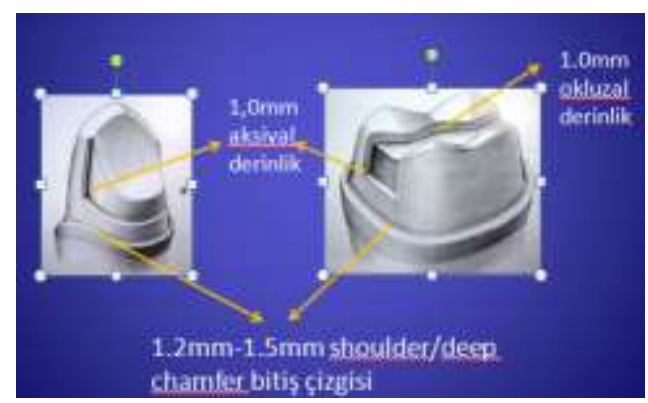

Resim 1. FGK restorasyonlar için ekstrakoronal anterior ve posterior diş preparasyon şekilleri. ${ }^{2}$

Laboratuar ortamında hazırlanacak olan restorasyonların preparasyonunda proteze giriş yolu oluşturmaya ve andırkat oluşturmamaya dikkat edilmelidir. Diş preparasyonunun tamamlanmasının ardından silikon esaslı ölçü maddesi ile ölçü alınır ve daylı model elde edilir. Daylara ince bir tabaka opak kompozit ile koping yapılır (Resim 2). Bu daylar üzerine fiber alt yapı, pontik bölgesinde daha yoğun olacak şekilde hazırlanır (Resim 3). FGK alt yapının üzerine veneer kompozit ile restorasyon tamamlanır. Hazırlanan restorasyonun dual-cure bir rezin simanla üretici firma önerilerine göre simantasyonu yapııır. ${ }^{2}$ protezler:

b. İntrakoronal parsiyel kaplamalı sabit

Eğer boşluğa komşu dişlerde hiç restorasyon yoksa veya kron içi dolgular mevcutsa, ilgili boşluğa implant yapılması uygun değilse intra koronal FGK restorasyonlar yapılabilir. İntra koronal FGK restorasyonlar direkt veya indirekt yöntemle yapılabilirler ve anterior ve posterior diş eksikliklerinde uygulanabilirler.

Preparasyona başlarken öncelikle mevcut olan eski restorasyonlar ve tüm çürük diş dokusu uzaklaştırılır. Eğer restorasyon indirekt yöntemle yapılacaksa dişlerin preparasyonunda andırkat oluşturmamaya dikkat edilmelidir. Anterior dişlerin preparasyonunda lingual yüzün ortasında $1.5 \mathrm{~mm}$ genişlik ve derinlikte oluk şeklinde bir kavite veya gövde alanına yakın 1-1.5 mm sınıf 3 kaviteye benzer bir inley kavitesi oluşturulabilir. ${ }^{41,49}$ Posterior bölgede yeterli fiber hacmini sağlamak için destek dişlerin okluzalinde inley kavitesine benzer preparasyon önerilir. Yaklaşık 2-2.5 mm derinlikte bir okluzal kavite preparasyonu hem fiberi kolayca yerleştirebilmek hem de veneer kompozite yer sağlamak için tavsiye edilir (Resim 4). ${ }^{41,48}$ Stresin en yoğun olduğu konnektör bölgesinde en az 4 mm'lik bir konnektör yüksekliği ve 3-4 mm'lik bir konnektör kalınlığı sağlamak için proksimal kavite preparasyonu yapılmalıdır. Bu preparasyon sayesinde karşıt dişle prematür temas önlenmiş olur. ${ }^{48}$ Behr ve ark. ${ }^{48}$ konnektör bölgesine daha yoğun fiber yerleştirebilmek için okluzal ve proksimal kavite birleşimini tüp şeklinde hazırlamışlardır. Genel olarak okluzal kavite genişliğinin premolarlarda $1,5-2 \mathrm{~mm}$, molarlarda $2,5-3 \mathrm{~mm}$ olması tavsiye edilir. ${ }^{48}$

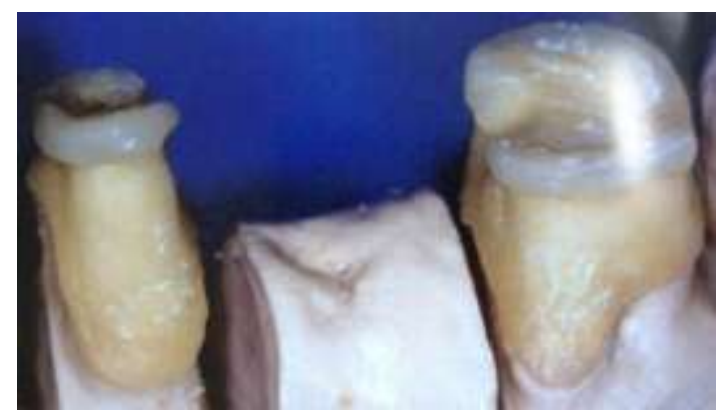

Resim 2. Daylara opak kompozit ile yapılan kopink görüntüsü. ${ }^{2}$

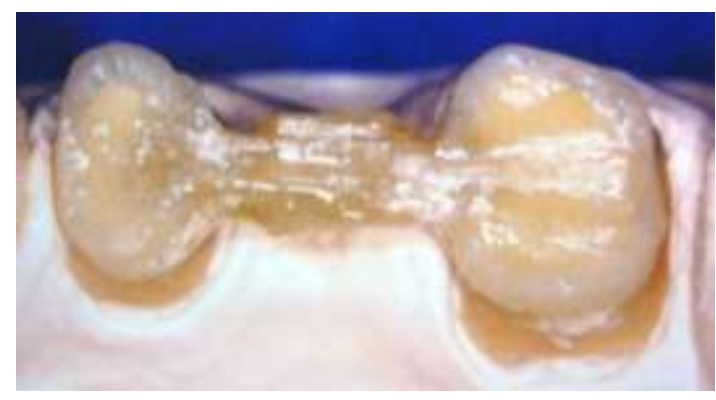

Resim 3. FGK alt yapının okluzal görünümü. ${ }^{2}$ 


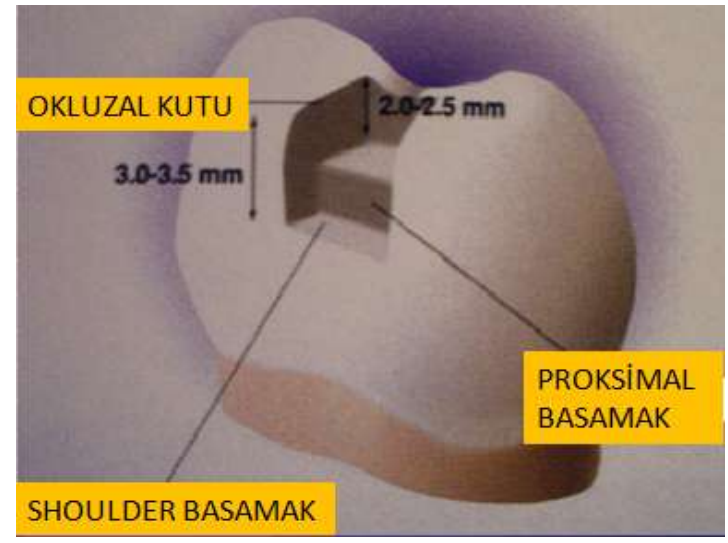

Resim 4. FGK restorasyonlar için intrakoronal diş preparasyon şekli. ${ }^{53}$

Direkt yöntemde kavite preparasyonlarının tamamlanmasını takiben, kavite yüzeylerine asit ve bonding ajan uygulanır. ${ }^{33}$ Kavite tabanlarına bir miktar akışkan kompozit konulup üzerine köprü uzunluğuna göre kesilip hazırlanmış fiber adapte edilip ışınlanır. ${ }^{33}$ Fiber alt yapının oluşturulmasının ardında üst yapı kompozit ile şekillendirilip restorasyon tamamlanır. ${ }^{33}$ Restorasyonun gövde bölgesi ayrıca fiber ile desteklenmelidir. ${ }^{42}$ Freilich $^{42}$, yaptığı bir çalışmada gövde bölgesinin desteklenmediği (low-volume design) restorasyonlarda üç ay sonra problem yaşandığını, bu nedenle restorasyonların şeklini değiştirerek gövde bölgelerini fiberle desteklediklerini (high-volume design) ve böylece restorasyonların dört yıl ya da daha uzun ömürlü olabileceğini bildirmiştir. kullanımı

c. İmplant üst yapılarının restorasyonunda

Klinik çalışmalar, tek yönlü fiberlerin implant üst yapılarında kullanılabileceğini göstermiştir. İmplant üst yapısı olarak hazırlanacak protez materyalleri, implant sistemi üzerine hassasiyetle uygulanabilmeli, yeterli mekanik dirence sahip olmalı, estetik ve maliyeti uygun olmalıdır. FGK'ler, bu özellikleri taşımaktadırlar. ${ }^{3}$

FGK materyalleri ile implant destekli sabit protez yapmanın avantajları arasında; önceden rezinle doyurulmuş fiberlerin iyi şekil verilebilme özelliği olması, döküm ve lehimleme gibi laboratuvar işlemlerinin olmamasından dolayı zaman kazanılması ve alt yapıya rezin veneerin kimyasal olarak bağlanması sayılabilir. İmplant destekli FGK restorasyonlar implant üst yapısına vida ile bağlanabilir (hibrit protezler) ya da yapıştırılabilir. Diş destekli protezler ile karşılaştırıldığında, FGK protezlerin üst yapılarının implant üst yapılarına olan bağlantısı üzerinde değişiklikler yapılabilir veya geliştirilebilir. Bunun nedeni; implant üst yapılarının işlenmesinin geleneksel olarak değil makinalar tarafından yapılmasıdır. $^{2}$

İmplant üstü FGK rezin köprü restorasyonları laboratuar ortamında hazırlanırlar. Ölçü alınıp model elde edilir ve implant üst yapılarının yerleştirilmesinin ardından karşıt dişler ile uyumu yapılır. İmplant üst yapılarının izolasyonu sağlanır ve FGK ile implant üst yapılarına öncelikle koping yapılır. Sonrasında implant üst yapıları etrafında fiber gövde bölgesinden çaprazlanarak sarılır ve köprü protezi oluşturulur (Resim 5). Gövde bölgesi ilave fiber ile güçlendirilir. Alt yapının tamamlanmasının ardından üst yapı veneer kompozit ile restore edilir ve restorasyon tamamlanır. Simantasyon rezin siman ile gerçekleştirilir. ${ }^{2,52}$

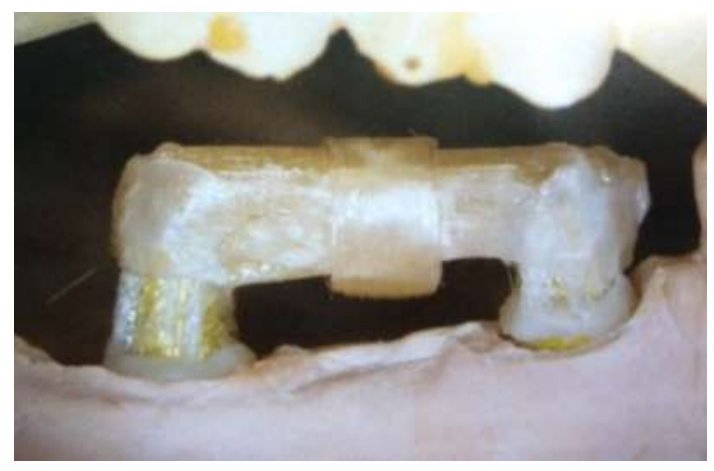

Resim 5. İmplant üstü restorasyonlarda alt yapının bitirilmiş görüntüsü. ${ }^{2}$

Vida üst yapılı implantlar için FGK'ler implant üst yapısının üzerine direkt olarak oturan, vida kanalı olan bir silindir yapı alt yapının ana parçasını oluşturur. $\mathrm{Bu}$ titanyum seramik silindir alt yapının fasial ve lingualde horizontal olukları ile proksimal kutuları mevcuttur. Bu silindir dizaynı FGK'lerin tutuculuğu için güvenilir bir yapı sergilemektedir. Horizontal oluklar makro mekanik tutuculuk sağlarken proksimal kutular vertikal olarak FGK restorasyona destek sağlar. Pürüzlendirilen ve silan sürülen seramik yapı, alaşıma beyaz bir görüntü sağlarken FGK'ler için ise mikro mekanik tutuculuk oluşturur. ${ }^{2}$ 


\section{SONUÇ}

İndirekt veya direkt yöntemlerle üretilen FGK restorasyonlarının başarıı olması için; yeterli miktarda fiberle güçlendirme, restorasyonun içindeki boşlukların minimalize edilmesi, fiberlerin rezine çok iyi bir şekilde doyurulması ve fiber alt yapı ile kompozit veneerlerin arasında iyi bir bağlantının olması gerekir.

FGK rezin köprülerin mekanik özellikleri ile ilgili yeterli çalışma olmaması ve yapılan klinik çalışmaların ise kesin bir değerlendirme yapacak kadar uzun süreli olmamasına rağmen; FGK rezin köprülerin diş dokuları için konservatif ve hasta açısından ekonomik olması, doğal ve estetik görünümleri, bu restorasyonları günümüz diş hekimliğinde bir tedavi seçeneği olarak kabul edilebilir hale getirmiştir.

\section{KAYNAKLAR}

1. McLean JW. The Science and Art of Dental Ceramics. Volume 1. The nature of dental ceramics and their clinical use. Chicago. 1th ed. Quintessence Publishing Co 1979; 115-82

2. Rosentiel SF, Land MF, Fujimoto J. Fiber reinforced composite fixed prostheses. In Contemporary Fixed Prosthodontics. Ed. Dolan J. 4th ed. Elsevier Mosby. St.Louis, Miss 2006; 830-40

3. Nağaş IÇ, Uzun G. Fiberle güçlendirilmiş kompozitlerin protetik uygulamalardaki yeri. Hacettepe Diş Hek Fak Derg 2009;33:49-60

4. Karaalioğlu $O$, Yeşil Duymuş $Z$. Fiberle güçlendirilmiş kompozitlerin sabit bölümlü protez yapımında kullanımları. Atatürk Üniv Diş Hek Fak Derg 2008;18:70-7

5. Gürbulak AG, Çölgeçen Ö, Kesim B. Fiberle güçlendirilmiş adeziv köprüler. Dicle Diş Hek Derg 2009;10:55-62

6. Başaran EG, Ayna E, Vallittu PK, Lassila LVJ. Load bearing capacity of fiber-reinforced and unreinforced composite resin cad/ cam-fabricated fixed dental prostheses. J Prosthet Dent 2013;109:88-94

7. Sfondrini MF, Massironi $S$, Pieraccini G, Scribante A, Vallittu PK, Lassila LV, Gandini P. Flexural strengths of conventional and nanofilled fiberreinforced composites: a three-point bending test. Dental Traumatology 2013;10.1111/edt.12055
8. Garoushi S, Yokoyama D, Shinya A, Vallittu PK. Fiber-reinforced composite resin prosthesis to restore missing posterior teeth: A case report. LJM 2007;AOP:070414.139-41

9. Scheiber CK. Polymethyl methacrylate reinforced with carbon fibers. Br Dent J. 1971;130:29-30.

10. Goldberg $\mathrm{AJ}$, Burstone $\mathrm{CJ}$. The use of continous fiber reinforcement in dentistry. Dent Mater 1992;8:197-202

11. Powell DB, Nicholls JI, Yuodelis RA, Strygler H. A comparision of wire and kevlar reinforced provisional restorations. Int $\mathrm{J}$ of Prosthodont 1994;7:81-89.

12. Heumen CCM, Dijken JWV, Tanner J, Pikaar R, Lassila LVJ, Creugers NHJ, Vallittu PK, Kreulen CM. Five-year survival of 3-unit fiber-reinforced composite fixed partial dentures in the posterior area. Dent Mater 2010;26:954-60

13. Heumen CCM, Dijken JWV, Tanner J, Pikaar R, Lassila LVJ, Creugers NHJ, Vallittu PK, Kreulen CM. Five-year survival of 3-unit fiber-reinforced composite fixed partial dentures in the anterior area. Dent Mater 2009;25:820-7

14. Yokoyama D, Shinya A, Gomi $H$, Vallittu PK, Shinya A. Effects of mechanical properties of adhesive resin cements on stress distribution in fiberreinforced composite adhesive fixed partial dentures. Dent Mater 2012;31:189-96

15. Vallıttu PK. Review of methods used to reinforce polymethlymethacrylate resin. J Prosthodont 1995;4:183-7

16. Mosharraf $\mathrm{R}$, Torkan S. Fracture resistance of composite fixed partial dentures reinforced with pre-impregnated and non-impregnated fiber. J Dent Res Dent Clin Dent Prospect 2012;6:12-6

17. Galan $D$, Lynch $E$. The effect of reinforcing fibres in dentures acrylics. J Irish Dent Assoc 1990;30:10913

18. Yu SH, Lee Y, Oh S, Cho HW, Oda Y, Bae JM. Reinforcing effects of different fibers on denture base resin based on the fiber type, concentration, and combination. Dent Mater 2012;31:1039-46

19. Cogswell FN. Thermoplastic aromatic polymer composites. Oxford: Butterworth- Heinemann 1992. 
20. Braden M, Davy KWM, Parker S, Ladızesky, NH, Ward, IM. Denture base polymethyl methacrylate reinforced with ultra-high modulus polyethylene fibres. Br Dent J 1988;164:109-13

21. Rudo DN, Karbhari VM. Physical behaviours of fiber reinforced composites as applied to tooth stabilization. Dent Clin North Am 1999;10-35

22. Vallitu PK. Comparison of the in vitro fatigue resistance of an acrylic resin removable partial denture reinforced with continuous glass fibers or metal wires. J Prosthodont 1996;5:115-21

23. Agrawal KK, Chand P, Mishra N, Singh K. Glass fiber reinforced composite fixed partial denture as provisional tooth replacement in pre-adolescent age: A clinical report, JID 2012;2:51-3

24. Ganesh M, Tandon S. Versatility of ribbond in contemporary dental practice trends. Biomater Artif Organs 2006;20:53-8

25. Çulhaoğlu KA. Fiberle güçlendirilmis indirekt kompozit sistemlerinin bazı fiziksel özelliklerinin ıps empress seramik sistemi ile karşılaştırılarak incelenmesi. Ankara Üniversitesi Sağlık Bilimleri Enstitüsü. Tez çalışması. 2007;1-31

26. Kürklü D, Yanıkoğlu ND, Sağsöz NP. Yapay porselen diş kullanılarak cam fiberle güçlendirilmiş kompozit rezin köprü uygulaması:3 olgu sunumu. Ege Üniv Diş Hek Fak Derg 2010;31:107-12

27. Vallittu PK. The effect of glass fibers reinforcement on the fracture resistance of a provisional fixed partial denture. J Prosthet Dent 1998;79:125-30

28. Waltimo T, Tanner J, Vallittu PK, Haapasalo M. Adherence of candida albicans to the surface of polymethylmethacrylate. e glass fiber composite used in dentures. Int J Prosthodont 1999;12:83-6

29. Marei MK. Reinforcement of denture base resins with glass fillers. J Prosthodont 1999;8:18-26

30. Spyrıdes SMM, Bastıan FL. In vitro comperativ-e study of the mechanical behavior of a composite matrix reinforced by two types of fibers (polyehylene and glass). Materials Science and Engineering 2004;24:671-7

31. Üstün $Y$, Demirboğa $S$, Ülker M. Üst orta keser diş eksikliğinin geçici olarak fiberle güçlendirilmiş adeziv köprü ile restorasyonu: Vaka raporu. Sağlık Bilimleri Dergisi 2010;19:209-15

32. Chen YC, Li H, Fok A. In vitro validation of a shape-optimized fiber-reinforced dental bridge. Dent Mater 2011;27:1299-37
33. Karaalioğlu O, Aladağ L. Cam fiber ile güçlendirilmiş kompozit restorasyon: Vaka raporu. Atatürk Üniv. Diş Hek Fak Derg 2009;19:111-4

34. Behr M, Rosentritt M, Handle G. Flexural properties of fiber reinforced using a vacum/pressure or a manual adaptation manufacturing process. J Dent 2000;28:509-14

35. Agrawal K, Chand P, Mishra N, Singh K. Glass fiber reinforced composite fixed partial denture as provisional tooth replacement in pre-adolescent age: A clinical report. JID 2012;2:51-3

36. Kumbuloglu O, Ozdemir N, Aksoy G, User A. A different pontic design for fiber-reinforced composite bridge works: A clinical report. Eur ] Dent 2007;1:50-3

37. Freilıch M, Meiers J. Fiber reinforced composites. Illinois: Quintessence Pub Co 2000

38. Eminkahyagil N. fiberle güçlendirilmiş kompozitlerin kullanımı. Tdbd 2004;84:43-4

39. Dyer SR, Lassila LV, Jokinen M, Valittu PK. Effect of fiber position and orientation on fracture load of fiber-reinforced composite. Dental Mater 2004;20:947-55

40. Yang HS, Lang LA, Felton DA. Finite element stress analysis on the effect of splinting in fixed partial dentures. J Prosthet Dent 1999;81:721-8

41. Rappelli G, Scalise L, Procaccini M, Tomasini EP. Stress distribution in fiber-reinforced composite inlay fixed partial dentures. J Prosthet Dent. 2005;93:425-32

42. Freilich MA, Meiers JC, Duncan JP, Eckrote KA, Goldberg AJ. Clinical evaluation of fiber-reinforced fixed bridges. J Am Dent Assoc 2002;133:152415346:1-6

43. Inderjeet K, Khandpur S, Kaur $H$. Replacing a missing anterior tooth with fiber reinforced composite bridge: A case report. JIDA 2011;5:5312

44. Ahlstrand WM, Finger WJ. Fiberle güçlendirilmiş direkt ve indirekt bölümlü protezler: Olgu sunumları. Quintessence 2002;6:59-5

45. Brunton PA. Fibre-reinforced fixed partial dentures: initial experiences. İn: Vallitu PK, editor. The Third İnternatıonal Sympposium on Fiber- Reinforced Plastics in Dentistry and Biometarials Research. University of Turku; 2003 
46. Garoushi S, Vallittu PK. Fiber-reinforced composites in fixed partial dentures. Libyan J Med 2006;AOP060802:1-6

47. Dixon DL, Breeding LC. The transvers strengths of three denture base resins reinforced with polyethylene fibers. J Prosthet Dent 1992;67:417-9

48. Edelhoff D, Spiekermann H, Yıldırım M. Metal-free inlay-retained fixed partial dentures. Quintessence Int 2001;4:269-81

49. Göehring TN, Peters OA, Lutz F. Marginal adaptation of inlay-retained adhesive fixed partial dentures after mechanical and thermal stress: An in vitro study. JProsthet Dent 2001;86:81-2

50. Monaco C, Baldissara P, Orologio GD, Scotti R. Short-term clinical evaluation of inlay and onlay restorations made with a ceromer. Int J Prosthodont 2001;14:81-6

51. Nilsson E, Alaeddin S, Karlsson S, Milleding P, Wennerberg A. Factors affecting the shear bond strength of bonded composite inlays. Int J Prosthodont 2000;13:52-8

52. Vallittu P K, CDT Alander P. University of Turku, Finland. İmplant supported glass fibre-reinforced composite fixed partial denture: A case report IPN=Interpenetrating Polymer Network Stick Tech Ltd., P.O.Pox 114, FIN-20521 Turku www.sticktech.com

53. Kurt EÇ, Özdoğan MÇ, Yılmaz H. Seromerler ve fiberle güçlendirilmiş kompozitler. Atatürk Üniv Diş Hek Fak Derg 2006;16:52-60

54. Garoushi S, Lassila LVJ, Vallitu PK. Fiber-reinforced conposite in clinical dentistry. CJDR 2009;12:7-4

\section{Yazışma Adresi \\ Nurten BAYSAL}

Gen. Dr. Tevfik Sağlam Cad.

GATA Dişhek. Bil. Mrk.Protez Bölümü Kat:1

06018 Etlik /ANKARA

Tel: 05058740324 (cep)

03123046053

Fax: 03123046020

e-Mail: nurtenerdogan7@hotmail.com 